\title{
Phytochemical and pharmacological
} investigations of different extracts of leaves and stem barks of Macropanax dispermus (Araliaceae): a promising ethnomedicinal plant

Syeda Rubaiya Afrin ${ }^{\dagger}$, Mohammad Rashedul Islam ${ }^{\dagger}$, Bibi Humayra Khanam, Nawreen Monir Proma, Sayeda Saima Didari, Sarah Waddun Jannat and Mohammed Kamrul Hossain*

\begin{abstract}
Background: Macropanax dispermus is traditionally used to treat various diseases by ethnic people. The present research reports the pharmacological properties with phytochemical profiling of the crude extracts of $M$. dispermus leaves (MDML), its n-hexane (MDHL), carbon tetrachloride (MDTL), chloroform (MDCL), ethyl acetate (MDEL), and aqueous (MDAL) fractions, and crude methanol extracts of its stem barks (MDMS). The in vitro thrombolytic activity was done on human erythrocytes whereas the cytotoxic activity was done by brine shrimp lethality assay. The in vivo analgesic activity was examined by acetic acid-induced writhing, tail immersion, and formalin-induced paw licking method. In contrast, antipyretic activity was done by the brewer's yeast-induced pyrexia method.

Results: $M D H L$ and MDMS showed $37.05 \%$ and $42.21 \%$ of significant $(p<0.01)$ thrombolytic activity, respectively. $\mathrm{MDCL}$ and MDMS showed the lower $\mathrm{LC}_{50}$ values of 23.15 and $37.11 \mu \mathrm{g} / \mathrm{ml}$ during cytotoxicity test, respectively. In acetic acid writhing method, MDTL and MDEL showed significant $(p<0.001)$ inhibition of writhing by $79.34 \%$ and $80.17 \%$, respectively. MDMS showed significant ( $p<0.001$ ) maximal possible effect (\%MPE) of 45.95\%, $62.26 \%, 65.79 \%, 89.69 \%$ and elongation of time in pain reaction of $48.53 \%, 60.28 \%, 58.76 \%$, and $70.14 \%$ at 30,60, 90, and 120 min intervals, respectively. MDML at $400 \mathrm{mg} / \mathrm{kg}$ exhibited significant $(p<0.001) 82.72 \%$ of inhibition of pain at the late phases. MDEL at $400 \mathrm{mg} / \mathrm{kg}$ of dose exhibited significant $(p<0.001)$ reduction of rectal temperature by $36.31 \%, 62.42 \%, 89.81 \%$, and $96.82 \%$ at $1,2,3$, and $4 \mathrm{~h}$ intervals, respectively.
\end{abstract}

Conclusion: The current research suggests that the plant extracts possess potential thrombolytic, cytotoxic, analgesic, and antipyretic activities.

Keywords: Macropanax dispermus, Phytochemicals, Thrombolytic, Cytotoxic, Analgesic, Antipyretic

*Correspondence: mkhossain73@yahoo.com; mkhossain19732017@gmail.com †'Syeda Rubaiya Afrin, Mohammad Rashedul Islam contributed equally to this work. Department of Pharmacy, Faculty of Biological Sciences, University of Chittagong, Chittagong 4331, Bangladesh

\section{Background}

From the ancient period, natural remedies have been popular with people due to their excellent medicinal properties which can treat complicated diseases without showing any side effects at minimum expense. The medicinal plants contain different types of naturally occurred chemical compounds that contribute to their medicinal properties. With the advancement of scientific research, the researchers have been successful to detect 
various phytochemical compounds in medicinal plants which are proved to exhibit different types of physiological activities and are used for prophylactic purposes [1].

Thrombosis is a lethal disease that causes vascular blockage and while recovering it causes fatal consequences, such as cerebral or myocardial infarction and even death [2]. Tissue plasminogen activator (t-PA), alteplase, anistreplase, urokinase, and streptokinase (SK), and recombinant t-PA therapies are currently used for the treatment of thrombosis [3]. The post-therapeutic adverse effects of these medicines are extremely significant which may cause further deterioration of a patient's health conditions [4]. These include intracranial hemorrhage [5], spontaneous pulmonary hemorrhage [6], angioedema [7], slow reperfusion rate, and frequent early re-occlusions which have decreased the use of thrombolytic drugs in many cases [8]. Cancer is another fatal disease that can cause abnormal cell growth, uncontrolled cell proliferation, differentiation, and ultimate death of the cells. The modern conventional treatment suggests chemotherapy, radiotherapy, or surgery fight against it which exhibited several adverse effects [9]. Natural cytotoxic agents may damage the cancerous cell and contribute to the treatment of cancer. Pain or algesia is generally an unpleasant sensation associated with tissue damage which is initially protective but responsible for many discomforts leading to adverse effects [10]. Analgesics are drugs used to treat or reduce the pain that act on the peripheral or central nervous system to selectively relieve pain without significantly altering consciousness [11]. The classical analgesic drugs are notably opiates and non-steroidal anti-inflammatory drugs (NSAIDs) [12]. Fever or pyrexia is an elevated body temperature above the normal level characterized by an increase in the thermoregulatory set-point, which results from the interaction of the central nervous and immune system. Fever is the body's natural defense mechanism against infectious agents that can damage the tissue [13]. NSAIDs also possess antipyretic activity. But NSAIDs exhibited severe adverse effects like ulceration, gastrointestinal bleeding, respiratory distress, drowsiness, nausea and along with these side effects opiates also exhibited constipation, physical dependence, addictive potential etc. [14].

Herbal medicines as the major remedy in the traditional system of medicine have been used in medical practices since antiquity [15]. In ancient literature, about 500 medicinal plants are mentioned and about 800 plants are used in the traditional system of medicine [16]. With the introduction of conventional medicines, scientists started to doubt the safety of traditional medicine because of a lack of proper scientific data. In the nineteenth century, human began to isolate the active principles of medicinal plants and was successful to invent quinine from Cinchona bark [17]. Such discoveries convinced scientists to rely on this alternative form of medicine and proceed to further investigations. Moreover, it has started to become popular with common people because of more effectiveness, fewer health hazard risks, and cheaper rates than conventional medicine. Thus the impact of phytochemistry led to the discovery of many of the effective conventional medicinal agents which were derived from plant sources and introduced anticancer drugs like vincristine, vinblastine, and paclitaxel [18], narcotic analgesics like morphine [19], and anti-malarial drugs like quinine and artemisinin [20]. Therefore, the current study focuses on the phytochemical and pharmacological investigations of an ethnomedicinal plant Macropanax dispermus.

Macropanax dispermus is a tree from the family of Araliaceae, and it is grown in evergreen forested areas. It was traditionally used for the treatment of digestion, postpartum bathing, eliminate waste matter, improve blood flow, cough, menopausal fever, and malarial fever by ethnic people of Thailand, Myanmar [21, 22]. Previous studies reported that its crude methanol extracts showed a good amount of vitamin E, carotene, xanthophylls, tannins, phenolics, and the highest amount of vitamin $C$ by using the $\beta$-carotene bleaching method [23].

So, the current research was conducted to investigate the phytochemical contents, thrombolytic, cytotoxic, analgesic, and antipyretic activity of the crude methanol extracts of the leaves and stem barks of $M$. dispermus and the solvent fractions of the crude methanol extracts of its leaves.

\section{Methods}

\section{Chemicals}

Methanol, n-hexane, carbon tetrachloride, chloroform, ethyl acetate, and other chemicals used for the extraction, solvent-solvent partitioning of plant materials, in vitro, and in vivo pharmacological tests were laboratory grade (Merck, Germany).

\section{Collection and identification of the plant}

The matured plant leaves and stem barks were collected in August 2018 with the help of a famous local traditional healer. Then it was identified by a renowned taxonomist under the herbarium no-sr20385.

\section{Preparation of crude extracts}

Plant materials (leaves and stem barks) were washed, chopped into small pieces, and semi-shed sun-dried for seven days. After drying, the plant materials were powdered with a mechanical grinder. Powder portions of the leaves $(1.36 \mathrm{~kg})$ and stem barks $(493 \mathrm{~g})$ of $M$. dispermus were soaked in $7.29 \mathrm{~L}$ and $2.60 \mathrm{~L}$ of methanol, 
respectively. After 13 days of occasional shaking, the solution was filtered and the filtrate was concentrated by evaporation method under reduced pressure at the temperature below $50{ }^{\circ} \mathrm{C}$ by using a rotary evaporator (Stuart, UK). The weight of the crude methanol extracts of $M$. dispermus leaves and stem barks was $28.50 \mathrm{gm}$. and 7.66 gm., respectively. The percentage (\%) yield of the extract was calculated using the following equation [14]:

$$
\% \text { Yield of extract }=\frac{\text { Weight of extrcated material }}{\text { Weight of crude powder }}
$$

The percentage of yield of crude methanol extracts of $M$. dispermus leaves and stem barks was $2.09 \%$ and $1.55 \%$, respectively.

\section{Solvent-solvent partitioning}

Crude methanol extracts of $M$. dispermus leaves were undergone solvent-solvent partitioning according to the protocol designed by Kupchan and Tsou and modified version of Wagenen et al. by using the solvents of $n$-hexane, carbon tetrachloride, chloroform, and ethyl acetate consecutively $[24,25]$.

\section{Qualitative phytochemical screening}

The preliminary phytochemical screening was done for evaluating the qualitative detection of terpenoids, flavonoids, saponins, phenol and tannins, phlobatannins, steroids, anthraquinones, alkaloids, glycosides, cardiac glycosides, resins, carbohydrates, proteins, fat and oil, and coumarin by using standard procedure [26-28]. The color intensity or the precipitate formation was used as analytical responses to these qualitative tests.

\section{Experimental animals}

Male Swiss Albino mice weighing approximately 20-30 g were used for experimental purposes. They were placed in standard propylene cages and familiarized under the controlled conditions (room temperature of $25 \pm 2{ }^{\circ} \mathrm{C}$, relative humidity of $60 \%-70 \%$ for 14 days) and operated with a $12 \mathrm{~h}$ light/dark cycle with food pellets. The mice were provided with a nutritionally adequate diet and drinking water ad libitum throughout the study. Diethyl ether anesthesia was employed on mice to euthanize. All the mice were sacrificed at the end of each experiment by using diethyl ether anesthesia. All segments of this report adhere to the ARRIVE Guidelines for reporting animal research. All experiments have been examined and approved by the ethical committee under approval no-cc98056.

\section{Acute toxicity study}

An acute toxicity study was conducted following the previously described method [29]. Each group comprises five Swiss albino mice and they fasted overnight before extract administration. Each group of animals was administered oral doses of 1000, 2000, 3000, and $4000 \mathrm{mg} / \mathrm{kg}$ of body weight of each of the extracts. After the administration of plant extract, they were restrained from food for further 3-4 h. Each animal was observed for the first $30 \mathrm{~min}$, then for the first $24 \mathrm{~h}$, and thereafter for 3 days. The mice were observed for any changes in the skin, fur, eyes, mucous membrane, respiration rate, circulatory rate, the central and autonomic nervous system at least once a day. The effective dose would be one-tenth of the median lethal dose $\left(\mathrm{LD}_{50}\right)$.

\section{Experimental design for in vivo testing}

During the evaluation of analgesic activity, 16 groups of mice were used for each investigation and five mice were selected for each group. Group (I) was treated as control (1\% tween-80 $10 \mathrm{ml} / \mathrm{kg}$ ), Group (II) was for standard (Diclofenac sodium $50 \mathrm{mg} / \mathrm{kg}$ used in acetic acid writhing study, and morphine sulfate $10 \mathrm{mg} / \mathrm{kg}$ served as the standard in both tail immersion and formalin-induced paw licking method) and others group were used for the administration of crude methanol extract of $M$. dispermus stem bark and leaves and its different extracted fractions at the dose of 200 and $400 \mathrm{mg} / \mathrm{kg}$. For brewer's yeast-induced antipyretic study, sixteen groups of mice were selected, numbered, five mice were assigned to each group. Group (I) was treated as control (1\% tween$8010 \mathrm{ml} / \mathrm{kg}$ ), Group (II) was for standard Paracetamol $(150 \mathrm{mg} / \mathrm{kg})$ and other groups were used for the administration of crude methanol extract of $M$. dispermus stem bark and leaves and its different extracted fractions at the dose of 200 and $400 \mathrm{mg} / \mathrm{kg}$. After each experimental period, all the treated mice were sacrificed using diethyl ether anesthesia.

\section{In vitro studies of Macropanax dispermus extracts Evaluation of thrombolytic activity}

Blood specimen Venous blood samples were drawn from 30 male and female healthy volunteers (age 18-26 years) who have no recent history of oral contraceptive and anticoagulant therapy. Ten blood samples were used for each concentration of each plant extracts. After that, $6 \mathrm{ml}$ of venous blood were drawn from each volunteer. Blood was collected and preserved by an expert senior medical technologist. A consent form was filed up for each volunteer for future reference.

Study design Experiments for clot lysis were carried out as reported earlier [30]. About $500 \mu \mathrm{l}$ of blood was taken into each pre-weighed Eppendorf tube and allowed to incubate at $37^{\circ} \mathrm{C}$ for $45 \mathrm{~min}$. After clot formation, fluid was completely released from each Eppendorf tubes and 
the clot weight was determined by subtracting the weight of the clot containing tube from the weight of the tube alone following the equation below:
$\%$ Mortality $=\frac{N \mathrm{~d}}{N} \times 100$

\section{Weight of Clot $=$ Weight of Clot Filled Eppendorf - Weight of Empty Eppendorf}

As standard, $100 \mu \mathrm{l}$ of Streptokinase (SK) and, as a negative non-thrombolytic control, $100 \mu \mathrm{l}$ of distilled water (DW) along with $100 \mu \mathrm{l}$ of each sample of different concentrations $(10 \mathrm{mg} / \mathrm{ml}, 8 \mathrm{mg} / \mathrm{ml}, 6 \mathrm{mg} / \mathrm{ml}, 3 \mathrm{mg} /$ $\mathrm{ml}, 1.5 \mathrm{mg} / \mathrm{ml}$ ) were separately added to the Eppendorf tubes. Then the Eppendorf tubes were incubated at $37^{\circ} \mathrm{C}$ for $90 \mathrm{~min}$. After incubation, the released fluid was discarded and tubes were again weighed to observe the difference in weight after clot disruption. Finally, the percentage (\%) of clot lysis was determined as follows:
Here $N_{\mathrm{d}}=$ Number of dead nauplii, $N=$ Number of nauplii taken.

\section{Determination of median lethal concentration ( $\left.\mathrm{LC}_{50}\right)$}

The $\mathrm{LC}_{50}$ value represented the concentration of the extract that produced death in half of the brine shrimp nauplii after a certain exposure time and was determined by the linear regression method from plotting $\%$ of mortality against the correspondent concentration of the extracts. An approximate linear correlation was observed

$$
\% \text { Clot Lysis }=\frac{\text { Weight of Clot Before Lysis }- \text { Weight of Clot Lysis }}{\text { Weight of Clot Before Lysis }} \times 100
$$

\section{Evaluation of cytotoxic activity}

Preparation of seawater Exactly 38 gm sea salt (without iodine) was dissolved in $1 \mathrm{~L}$ of distilled water and filtered off to get a clear solution. The $\mathrm{pH}$ of the seawater was maintained between $8.0-8.5$ by applying $1 \mathrm{~N} \mathrm{NaOH}$ solution [31].

Hatching of brine shrimp Artemia salina leach (brine shrimp eggs) was collected from pet shops in Chittagong, used as the test organism. Seawater was taken in the small tank and shrimp eggs were added to the seawater in the tank. After 2 days $(48 \mathrm{~h})$ of hatching, the eggs would be matured as nauplii. The oxygen was supplied constantly through the oxygen pump during hatching time. The hatched shrimps were attracted to the light (phototaxis) and so nauplii free from eggshell was collected from the illuminated part of the tank. The nauplii were taken from the fish tank by a pipette.

Study design Five milliliters of each of the plant extract solutions of different concentrations (1000, $500,250,125,62.5 \mu \mathrm{g} / \mathrm{ml}$ ) was added to $5 \mathrm{ml}$ of seawater containing 10 nauplii. After $24 \mathrm{~h}$, the Petri dishes were inspected using a magnifying glass against a black background and the number of survived nauplii in each was counted. The mortality endpoint of this bioassay was determined as the absence of controlled forward motion during $30 \mathrm{~s}$ of observation. From these data, the percentage (\%) of the mortality of the brine shrimp nauplii was calculated for each concentration from the following equation [32]: when concentration versus the percentage of mortality was plotted on the graph paper and the concentrationresponse data were transformed into a straight line utilizing a trend line fit linear regression analysis (Microsoft Excel 2007). The $\mathrm{LC}_{50}$ values were derived from the bestfit line obtained.

\section{In vivo studies of Macropanax dispermus extracts Evaluation of analgesic activity}

Acetic acid-induced writhing method This method was an analgesic behavioral observation assessment method that demonstrated a noxious stimulation in mice. This study was carried out using the method of Koster as modified by Dambisya and Lee [33, 34]. Fifteen minutes after administration of standard and $30 \mathrm{~min}$ after administration of the extract, $0.7 \%$ glacial acetic acid $(10 \mathrm{ml} / \mathrm{kg})$ was injected intraperitoneally (IP) to all the mice to induce pain characterized by abdominal constrictions or writhes. 5 min later, each mouse of all groups was observed to count the number of writhes for 20 min carefully and recorded. After each observation period, all the treated mice were euthanized using diethyl ether anesthesia. The percentage inhibition against abdominal writhing was used to assess the degree of analgesia and was calculated using the formula:

$$
\% \text { of Pain Inhibition }=\frac{N_{\mathrm{c}}-N_{\mathrm{t}}}{N_{\mathrm{c}}}
$$

Here $N_{\mathrm{c}}=$ number of writhings in the control group, and $N_{\mathrm{t}}=$ number of writhings in the treatment group. 
Tail immersion method This was a thermal method that was performed to evaluate the central analgesic property of the investigated extracts. The method described by Di Stasi et al. [35] was used for this experiment. Before $30 \mathrm{~min}$ of treatment about $2-3 \mathrm{~cm}$ of the tail of each of the mice was dipped into a water bath containing warm water maintained at a temperature of $50 \pm 1{ }^{\circ} \mathrm{C}$ and the time taken for the mice to withdraw its tail from the warm water was recorded. The animals, which showed a flicking response within 3-5 s, were selected for the study. A cut-off period of $15 \mathrm{~s}$ was determined to avoid damage to the tail. After baseline, the treated mice were tested at 30 , 60,90 , and $120 \mathrm{~min}$ after drug administration [36]. While measurements were being made, animals were briefly immobilized by wrapping them gently. After each observation period, all the treated mice were euthanized using diethyl ether anesthesia. The percentage of the Maximal Possible Effect (\% MPE) was calculated using the following equation [37]:

$$
\% \text { of MPE }=\frac{\text { Post-drug Latency }- \text { Pre-drug Latency }}{\text { Cut off time }- \text { Pre-drug Latency }} \times 100
$$

The percentage of time elongation was calculated from the following equation [38]:

$$
\% \text { of Elongation of Latency }=\frac{\text { Latency of Treatment }- \text { Latency of Control }}{\text { Latency of Treatment }} \times 100
$$

Formalin-induced paw licking method This was a persistent-pain model that was used to assess both central and peripheral analgesic effects of the investigated extracts. This analgesic assay was done using a previously described method [39]. After sixty minutes of administration of control, standard, and investigated extracts, $20 \mu \mathrm{l}$ of $1 \%$ formalin solution was injected through the subplantar route into the right hind paw of each mouse. The time (in seconds) spent licking or biting the injected paw indicated pain and was recorded. After subplantar injection of formalin, the responses of the mice were noticed for the first 5 min (early or neurogenic phase) and 15-30 min (late or inflammatory phase). After each observation period, all the treated mice were euthanized using diethyl ether anesthesia. The percentage (\%) of pain inhibition was calculated using the following formula:

$$
\% \text { Inhibition of Pain }=\frac{\text { Reaction Time }(\text { Control })-\text { Reaction Time }(\text { Treatment })}{\text { Reaction Time }(\text { Control })} \times 100
$$

\section{Results \\ Qualitative phytochemical screening}

The current study was carried out to screen the presence or absence of preliminary phytochemicals in the investigated extracts which showed the presence of different types of phytochemicals in the extracts which are demonstrated in Table 1.

\section{Acute toxicity study}

No mice showed any abnormal changes such as reduced

\section{Evaluation of antipyretic activity}

The antipyretic effect was assessed by using the brewer's yeast-induced pyrexia method described by Adams et al. [40]. Before experimentation, the rectal temperature motor activity, restlessness, convulsions, coma, diarrhea, and lacrimation at the experimental doses of each of the investigational extracts. No mice were dead at the 
Table 1 Preliminary screening of phytochemicals of the investigated extracts of $M$. dispermus leaves and stem barks

\begin{tabular}{|c|c|c|c|c|c|c|c|c|}
\hline Phytochemicals & Methods & MDML & MDHL & MDTL & MDCL & MDEL & MDAL & MDMS \\
\hline \multirow[t]{2}{*}{ Terpenoids } & Salkowski's test & + & - & - & + & - & + & + \\
\hline & Liebermann-Burchard's test & ++ & - & - & ++ & - & ++ & ++ \\
\hline \multirow[t]{4}{*}{ Flavonoids } & Alkaline reagent test & - & - & - & - & - & + & + \\
\hline & $\begin{array}{l}\text { Zinc-hydrochloric acid reduction } \\
\text { test }\end{array}$ & ++ (Flavonol) & + (Flavone) & - & + (Flavono-ids) & - & - & $++($ Flavono-l) \\
\hline & Lead acetate solution test & + & - & - & - & - & + & ++ \\
\hline & Sulfuric acid test & ++ & - & - & - & - & + & ++ \\
\hline Saponins & Foam test & +++ & - & - & - & - & +++ & ++ \\
\hline Phenols and tannins & Ferric chloride test & + & - & - & - & - & - & +(Phenol) \\
\hline Phlobatannins & Hydrochloric acid test & + & - & - & - & - & - & ++ \\
\hline \multirow[t]{2}{*}{ Steroid } & Salkowski's test & + & - & - & - & - & - & - \\
\hline & Liebermann-Burchard's test & - & - & - & - & - & - & - \\
\hline \multirow[t]{2}{*}{ Anthraquinones } & Acid test & ++ & + & - & - & - & - & ++ \\
\hline & Hydroxy-anthraquinone test & ++ & - & - & - & - & - & + \\
\hline \multirow[t]{3}{*}{ Alkaloids } & Mayer's test & ++ & - & - & - & - & - & + \\
\hline & Wagner's test & ++ & - & - & - & - & - & + \\
\hline & Hager's test & ++ & - & - & - & - & - & + \\
\hline \multirow[t]{3}{*}{ Glycosides } & Sodium hydroxide reagent test & - & - & - & + & - & + & + \\
\hline & Liebermann's test & + & - & - & + & - & - & - \\
\hline & Salkowski's test & + & - & - & - & - & - & + \\
\hline \multirow[t]{2}{*}{ Cardiac glycosides } & Keller-Killiani test & + & - & - & - & - & + & ++ \\
\hline & Baljet's test & + & - & - & + & - & + & ++ \\
\hline Resins & Acetone test & - & - & - & - & - & - & + \\
\hline \multirow[t]{4}{*}{ Carbohydrates } & Benedict's test & - & - & - & - & - & - & ++ \\
\hline & Molisc-h's test & + & - & + & - & - & - & ++ \\
\hline & lodine test & - & - & - & - & - & - & - \\
\hline & Fehling's test & + & - & - & - & - & - & ++ \\
\hline \multirow[t]{2}{*}{ Proteins } & Biuret test & + & - & - & + & + & - & - \\
\hline & Nitric acid test & ++ & - & - & - & - & + & + \\
\hline Fats and fixed oils & Copper sulfate test & + & - & + & - & - & - & + \\
\hline Coumarin & Sodium hydroxide test & - & - & - & - & - & - & - \\
\hline
\end{tabular}

$"+"=$ Present, $"++"=$ More presence, $"+++"=$ Very much presence,,$"=$ Absent, MDML =Crude methanol extract of $M$. dispermus leaves, $\mathrm{MDHL}=\mathrm{n}-\mathrm{hexane}$ fraction of crude methanol extracts of $M$. dispermus leaves, $M D T L=$ Carbon tetrachloride fraction of crude methanol extracts of $M$. dispermus leaves, $\mathrm{MDCL}=\mathrm{Ch}$ loroform fraction of crude methanol extracts of $M$. dispermus leaves, $M D E L=$ Ethyl acetate fraction of crude methanol extracts of $M$. dispermus leaves, $M D A L=A q u e o u s$ fraction of crude methanol extracts of $M$. dispermus leaves, MDMS = Crude methanol extract of $M$. dispermus stem bark

experimental doses. So, the $\mathrm{LD}_{50}$ was investigated to be greater than $4000 \mathrm{mg} / \mathrm{kg}$.

\section{In vitro studies of Macropanax dispermus extracts Evaluation of thrombolytic activity}

The thrombolytic activity of the investigated extracts was determined as a part of the exploration of cardio-protective drugs from plant reserves. The results conferred in Table 2 showed that among multiple extracts, MDMS, MDML, MDHL, and MDCL produced significant $(p<0.001)$ clot lysis $(\%)$ in a concentration-dependent manner. Among them, MDMS and its MDHL fraction showed $42.21 \%$ and $37.05 \%$ clot lysis at the dose of $10 \mathrm{mg} / \mathrm{ml}$ respectively, compared to others.

\section{Evaluation of cytotoxic activity}

The level of toxicity against brine shrimp was classified as toxic having an $\mathrm{LC}_{50}$ value less than $1000 \mu \mathrm{g} / \mathrm{ml}$ and noncytotoxic having an $\mathrm{LC}_{50}$ value greater than $1000 \mu \mathrm{g} / \mathrm{ml}$ [42]. The brief results displayed in Table 3 indicate that the MDCL, MDEL, MDAL, and MDMS produced high cytotoxicity with the lowest $\mathrm{LC}_{50}$ values whereas MDML and its MDHL, MDTL fractions were observed to be non-cytotoxic. Among these extracts, MDCL fraction and crude MDMS showed cytotoxicity with the lowest $\mathrm{LC}_{50}$ values of 23.15 and $37.11 \mu \mathrm{g} / \mathrm{ml}$, respectively, compared to others. However, positive control vincristine sulfate was observed to be a highly cytotoxic substance. 
Table 2 Thrombolytic activity of the investigated extracts of $M$. dispermus leaves and stem barks

\begin{tabular}{|c|c|}
\hline Group & $\begin{array}{l}\text { Mean } \pm \text { SEM \% } \\
\text { of clot lysis }\end{array}$ \\
\hline Control & $3.71 \pm 0.44$ \\
\hline Standard (streptokinase) & $64.72 \pm 1.88^{* * *}$ \\
\hline MDML (10 mg/ml) & $27.36 \pm 3.83^{* *}$ \\
\hline MDML (8 mg/ml) & $25.01 \pm 3.97$ \\
\hline MDML (6 mg/ml) & $23.44 \pm 3.32^{* *}$ \\
\hline MDML (3 mg/ml) & $9.38 \pm 1.63$ \\
\hline MDML (1.5 mg/ml) & $7.81 \pm 0.88$ \\
\hline MDHL (10 mg/ml) & $37.05 \pm 2.69^{* * *}$ \\
\hline MDHL (8 mg/ml) & $36.27 \pm 1.70^{* * *}$ \\
\hline MDHL $(6$ mg/ml) & $27.89 \pm 2.18^{* * *}$ \\
\hline MDHL (3 mg/ml) & $22.89 \pm 1.79 * * *$ \\
\hline MDHL(1.5 mg/ml) & $12.62 \pm 1.89$ \\
\hline MDTL (10 mg/ml) & $15.95 \pm 1.96^{*}$ \\
\hline MDTL(8 mg/ml) & $13.62 \pm 1.64^{*}$ \\
\hline MDTL (6 mg/ml) & $12.28 \pm 1.46^{*}$ \\
\hline MDTL (3 mg/ml) & $10.49 \pm 1.04^{*}$ \\
\hline MDTL (1.5 mg/ml) & $9.89 \pm 0.96^{*}$ \\
\hline $\operatorname{MDCL}(10$ mg/ml) & $29.81 \pm 1.71^{* * *}$ \\
\hline $\mathrm{MDCL}(8 \mathrm{mg} / \mathrm{ml})$ & $21.17 \pm 1.92^{* *}$ \\
\hline $\mathrm{MDCL}(6$ mg/ml) & $15.61 \pm 1.45^{* *}$ \\
\hline MDCL (3 mg/ml) & $12.32 \pm 0.89 * * *$ \\
\hline MDCL $(1.5$ mg/ml) & $9.52 \pm 1.03^{*}$ \\
\hline MDEL $(10$ mg/ml) & $16.15 \pm 1.36^{* *}$ \\
\hline MDEL (8 mg/ml) & $8.49 \pm 1.41$ \\
\hline MDEL (6 mg/ml) & $7.85 \pm 0.73$ \\
\hline MDEL (3 mg/ml) & $6.26 \pm 0.93$ \\
\hline MDEL $(1.5 \mathrm{mg} / \mathrm{ml})$ & $3.52 \pm 0.90$ \\
\hline MDMS (10 mg/ml) & $42.21 \pm 1.84^{* * *}$ \\
\hline MDMS (8 mg/ml) & $29.27 \pm 2.71^{* *}$ \\
\hline MDMS (6 mg/ml) & $26.89 \pm 2.73^{* *}$ \\
\hline MDMS (3 mg/ml) & $18.40 \pm 1.66^{* *}$ \\
\hline MDMS (1.5 mg/ml) & $17.89 \pm 2.36^{*}$ \\
\hline
\end{tabular}

The results were expressed in Mean \pm SEM (standard mean error) ${ }^{*} p<0.05$, ${ }^{* *} p<0.01$, and ${ }^{* *} p<0.001$ were considered as statistically significant. The statistical analysis followed by one-way analysis of variance (Dunnett's test) compared to the control. MDML $=$ Crude methanol extract of $M$. dispermus leaves, $\mathrm{MDHL}=\mathrm{n}$-hexane fraction of crude methanol extract of $M$. dispermus leaves, MDTL $=$ Carbon tetrachloride fraction of crude methanol extract of $M$. dispermus leaves, $\mathrm{MDCL}=$ Chloroform fraction of crude methanol extract of $M$. dispermus leaves, MDEL $=$ Ethyl acetate fraction of crude methanol extract of $M$. dispermus leaves, $\mathrm{MDMS}=$ Crude methanol extract of $M$. dispermus stem barks

\section{In vivo studies of Macropanax dispermus extracts Evaluation of analgesic activity}

Acetic acid-induced writhing method In this method, the investigated extracts at the doses of 200 and $400 \mathrm{mg} / \mathrm{kg}$ body weight showed a decrease in the number of writhing in rodents as compared to control. Among them, MDML and its MDCL, MDEL, MDTL fractions, and MDMS pro-
Table 3 Cytotoxic activity of the multiple extracts of $M$. dispermus leaves and stem barks

\begin{tabular}{lllc}
\hline Sample & Equation & $R^{2}$ & $\mathbf{L C}_{\mathbf{5 0}}(\boldsymbol{\mu g} \mathbf{g} \mathbf{m l})$ \\
\hline $\begin{array}{lll}\text { Standard (vincris- } \\
\text { tine sulfate) }\end{array}$ & $y=4.978 x+49.32$ & $R^{2}=0.820$ & 0.14 \\
MDML & $y=0.028 x+2.916$ & $R^{2}=0.914$ & 1681.57 \\
MDHL & $y=0.021 x+4.166$ & $R^{2}=0.806$ & 2579.33 \\
MDTL & $y=0.018 x+5$ & $R^{2}=0.677$ & 2500.00 \\
MDCL & $y=0.054 x+48.75$ & $R^{2}=0.874$ & 23.15 \\
MDEL & $y=0.059 x+45$ & $R^{2}=0.898$ & 84.75 \\
MDAL & $y=0.082 x+22.08$ & $R^{2}=0.957$ & 340.49 \\
MDMS & $y=0.045 x+48.33$ & $R^{2}=0.915$ & 37.11 \\
\hline
\end{tabular}

The results were expressed in Mean \pm SEM (standard mean error) ${ }^{*} p<0.05$, ${ }^{* *} p<0.01$, and ${ }^{* * *} p<0.001$ were considered as statistically significant. The statistical analysis followed by one-way analysis of variance (Dunnett's test) compared to the control. MDML $=$ Crude methanol extract of $M$. dispermus leaves, $\mathrm{MDHL}=\mathrm{n}$-hexane fraction of crude methanol extract of $M$. dispermus leaves, MDTL $=$ Carbon tetrachloride fraction of crude methanol extract of $M$. dispermus leaves, $M D C L=$ Chloroform fraction of crude methanol extract of $M$. dispermus leaves, MDEL = Ethyl acetate fraction of crude methanol extract of M. dispermus leaves, MDAL = Aqueous fraction of crude methanol extract of $M$. dispermus leaves, $\mathrm{MDMS}=$ Crude methanol extract of $M$. dispermus stem barks

Table 4 Analgesic effect of the investigated extracts of $M$. dispermus leaves and stem barks on acetic acid-induced writhing test

\begin{tabular}{lcc}
\hline Groups & No. of writhing & $\begin{array}{c}\text { Inhibition of } \\
\text { writhing (\%) }\end{array}$ \\
\hline Control & $48.40 \pm 1.44$ & - \\
Diclofenac Sodium (50 mg/kg) & $4.20 \pm 0.86^{* * *}$ & 91.32 \\
MDML (200 mg/kg) & $11.80 \pm 1.43^{* * *}$ & 75.62 \\
MDML (400 mg/kg) & $7.60 \pm 1.03^{* * *}$ & 84.30 \\
MDHL (200 mg/kg) & $19.00 \pm 1.22^{* * *}$ & 60.74 \\
MDHL (400 mg/kg) & $11.20 \pm 0.86^{* * *}$ & 76.86 \\
MDTL (200 mg/kg) & $18.00 \pm 1.38^{* * *}$ & 62.81 \\
MDTL (400 mg/kg) & $10.00 \pm 1.64^{* * *}$ & 79.34 \\
MDCL (200 mg/kg) & $14.20 \pm 1.39^{* * *}$ & 70.66 \\
MDCL (400 mg/kg) & $8.60 \pm 0.68^{* * *}$ & 82.23 \\
MDEL (200 mg/kg) & $11.40 \pm 1.72^{* * *}$ & 76.45 \\
MDEL (400 mg/kg) & $9.60 \pm 0.93^{* * *}$ & 80.17 \\
MDAL (200 mg/kg) & $22.20 \pm 2.82^{* * *}$ & 54.13 \\
MDAL (400 mg/kg) & $13.20 \pm 2.52^{* * *}$ & 72.73 \\
MDMS (200 mg/kg) & $14.40 \pm 1.63^{* * *}$ & 70.25 \\
MDMS (400 mg/kg) & $11.20 \pm 1.24^{* * *}$ & 76.86
\end{tabular}

The results were expressed in Mean \pm SEM (standard mean error) * $p<0.05$, ${ }^{* *} p<0.01$, and ${ }^{* * *} p<0.001$ were considered as statistically significant. The statistical analysis followed by one-way analysis of variance (Dunnett's test) compared to the control. MDML $=$ Crude methanol extract of $M$. dispermus leaves, $\mathrm{MDHL}=\mathrm{n}$-hexane fraction of crude methanol extract of $M$. dispermus leaves, $M D T L=$ Carbon tetrachloride fraction of crude methanol extract of $M$. dispermus leaves, $\mathrm{MDCL}=$ Chloroform fraction of crude methanol extract of $M$. dispermus leaves, $\mathrm{MDEL}=$ Ethyl acetate fraction of crude methanol extract of $M$. dispermus leaves, MDAL $=$ Aqueous fraction of crude methanol extract of $M$. dispermus leaves, MDMS $=$ Crude methanol extract of $M$. dispermus stem barks 
duced a significant $(p<0.001)$ decrease in the number of writhing (i.e., \% inhibition of writhing) which demonstrated their higher effectiveness as peripheral analgesic agents as revealed in Table 4. Furthermore, MDML and its MDEL fraction comparatively showed the highest percentage of inhibition of writhing observed with both doses, 200 and $400 \mathrm{mg} / \mathrm{kg}$ relative to others.

Tail immersion method The extracts at doses of 200 and $400 \mathrm{mg} / \mathrm{kg}$ body weight showed a different level of increase in pain reaction time (PRT), percentage of maximal possible effect (\%MPE), and percentage elongation of latency as compared to control in a dose-dependent manner. The 200 and $400 \mathrm{mg} / \mathrm{kg}$ doses of MDML, MDEL, MDAL, and MDMS showed significant $(p<0.001)$ analgesic activity. The same extracts exhibited a significant increase in PRT, higher \%MPE, and percentage elongation of latency until $120 \mathrm{~min}$. The \%MPE of these extracts remained elevated throughout the observation period. In contrast, the standard morphine sulfate $(10 \mathrm{mg} / \mathrm{kg})$ increased the level significantly. MDML, MDEL, and MDMS demonstrated higher analgesic effects in both the acetic acid-induced writhing method and tail immersion method which indicated these extracts might show analgesic effect both peripherally and centrally. Among those, crude MDML and MDMS exhibited the highest effect in both methods. The results of PRT and \%MPE are shown in Table 5, and the percentages of elongation of latency are presented in Table 6.

Formalin-induced paw licking method In this method, the experimental extracts (200 and $400 \mathrm{mg} / \mathrm{kg}$ body weight) showed a greater percentage (\%) of pain inhibition in the late phase than that of the early phase of investigation as compared to control in mice significantly $(p<0.001)$. They exhibited their potential to give the analgesic effect peripherally more than centrally. Crude extracts MDML and MDMS showed significant peripheral and central analgesic effects which are observed with both doses (200 and $400 \mathrm{mg} / \mathrm{kg}$ ). However, MDTL, MDCL, MDEL fractions of MDML extract produced significant $(p<0.001)$ analgesia peripherally. These results were tabulated in Table 7.

\section{Evaluation of antipyretic activity}

In brewer's yeast-induced pyrexia method, MDML and its related MDHL and MDEL fractions significantly reduced the rectal temperature $(p<0.001)$ after the $1 \mathrm{~h}$ of extract administration at the doses of 200 and $400 \mathrm{mg} / \mathrm{kg}$ body weight. All other investigated extracts (200 and $400 \mathrm{mg} /$ $\mathrm{kg}$ ) reduced the rectal temperature of Swiss albino mice as compared to control significantly $(p<0.001)$ on total $(4 \mathrm{~h})$ experimental period as displayed in Table 8. The MDTL, MDEL, MDHL fractions of MDML showed an increased reduction of rectal temperature. The percent decrease in

Table 5 Analgesic effect of the investigated extracts of $M$. dispermus leaves and stem barks on tail immersion test

\begin{tabular}{|c|c|c|c|c|c|}
\hline \multirow[t]{2}{*}{ Group } & \multicolumn{5}{|c|}{ Pain reaction time in seconds (\% MPE) } \\
\hline & Pretreatment & $30 \mathrm{~min}$ & $60 \mathrm{~min}$ & $90 \mathrm{~min}$ & $120 \mathrm{~min}$ \\
\hline Control & $3.57 \pm 0.43$ & $4.69 \pm 0.35(9.77 \%)$ & $4.32 \pm 0.35(6.58 \%)$ & $4.65 \pm 0.40(9.42 \%)$ & $4.14 \pm 0.34(5.01 \%)$ \\
\hline Morphine sulfate (10 mg/kg) & $3.96 \pm 0.30$ & $11.06 \pm 0.35^{* * *}(64.31 \%)$ & $12.52 \pm 0.44^{* * *}(77.51 \%)$ & $14.24 \pm 0.57^{* * *}(93.15 \%)$ & $14.36 \pm 0.17^{* * *}(94.18 \%)$ \\
\hline MDML (200 mg/kg) & $3.88 \pm 0.33$ & $5.65 \pm 0.22(15.90 \%)$ & $8.95 \pm 0.33^{* * *}(45.62 \%)$ & $10.08 \pm 0.47^{* * *}(55.78 \%)$ & $13.07 \pm 0.42^{* * *}(82.66 \%)$ \\
\hline MDML (400 mg/kg) & $3.54 \pm 0.46$ & $7.95 \pm 0.46^{* * *}(38.47 \%)$ & $10.31 \pm 0.38^{* * *}(59.10 \%)$ & $13.07 \pm 0.64^{* * *}(83.12 \%)$ & $13.77 \pm 0.50^{* * *}(89.28 \%)$ \\
\hline MDHL (200 mg/kg) & $3.92 \pm 0.49$ & $8.08 \pm 0.52^{* * *}(37.52 \%)$ & $8.77 \pm 0.62^{* * *}(43.76 \%)$ & $8.40 \pm 0.43^{* * *}(40.44 \%)$ & $7.10 \pm 0.37^{* *}(28.75 \%)$ \\
\hline MDHL (400 mg/kg) & $3.87 \pm 0.48$ & $10.83 \pm 0.59^{* * *}(62.52 \%)$ & $10.98 \pm 0.58^{* * *}(63.89 \%)$ & $12.01 \pm 0.73^{* * *}(73.12 \%)$ & $8.48 \pm 0.31^{* * *}(41.47 \%)$ \\
\hline MDTL (200 mg/kg) & $3.75 \pm 0.22$ & $5.57 \pm 0.23(16.14 \%)$ & $7.59 \pm 0.22^{* *}(34.13 \%)$ & $9.83 \pm 0.68^{* * *}(54.03 \%)$ & $6.83 \pm 0.32^{* *}(27.41 \%)$ \\
\hline MDTL (400 mg/kg) & $4.19 \pm 0.25$ & $7.99 \pm 0.55^{* * *}(35.13 \%)$ & $9.88 \pm 0.52^{* * *}(52.63 \%)$ & $12.15 \pm 0.83^{* * *}(73.66 \%)$ & $8.83 \pm 0.53^{* * *}(42.93 \%)$ \\
\hline MDCL (200 mg/kg) & $3.86 \pm 0.17$ & $5.25 \pm 0.30(12.51 \%)$ & $6.94 \pm 0.66^{*}(27.66 \%)$ & $8.18 \pm 0.30^{* *}(38.77 \%)$ & $7.72 \pm 0.53^{* * *}(34.69 \%)$ \\
\hline MDCL (400 mg/kg) & $4.34 \pm 0.24$ & $6.12 \pm 0.20(16.77 \%)$ & $8.65 \pm 0.59^{* * *}(40.49 \%)$ & $10.09 \pm 0.79^{* * *}(53.94 \%)$ & $9.31 \pm 0.32^{* * *}(46.62 \%)$ \\
\hline MDEL (200 mg/kg) & $3.88 \pm 0.30$ & $5.24 \pm 0.24(12.28 \%)$ & $7.28 \pm 0.20^{* *}(30.57 \%)$ & $7.31 \pm 0.38^{*}(30.88 \%)$ & $7.99 \pm 0.37^{* * *}(37.04 \%)$ \\
\hline MDEL (400 mg/kg) & $4.63 \pm 0.30$ & $8.06 \pm 0.44^{* * *}(33.05 \%)$ & $9.15 \pm 0.63^{* * *}(43.6 \%)$ & $9.87 \pm 0.40^{* * *}(50.55 \%)$ & $10.43 \pm 0.28^{* * *}(55.95 \%)$ \\
\hline MDAL (200 mg/kg) & $3.38 \pm 0.80$ & $5.72 \pm 0.36(20.12 \%)$ & $9.62 \pm 0.44^{* * *}(53.73 \%)$ & $10.89 \pm 0.39^{* * *}(64.62 \%)$ & $12.62 \pm 0.90^{* * *}(78.49 \%)$ \\
\hline MDAL (400 mg/kg) & $3.42 \pm 0.18$ & $6.71 \pm 0.35^{* *}(28.42 \%)$ & $11.03 \pm 0.72^{* * *}(65.76 \%)$ & $13.58 \pm 0.43^{* * *}(87.71 \%)$ & $13.79 \pm 0.72^{* * *}(89.52 \%)$ \\
\hline MDMS (200 mg/kg) & $4.09 \pm 0.38$ & $6.43 \pm 0.34(21.43 \%)$ & $8.77 \pm 0.82^{* * *}(42.85 \%)$ & $7.06 \pm 0.63^{*}(27.21 \%)$ & $11.80 \pm 0.55^{* * *}(70.65 \%)$ \\
\hline MDMS (400 mg/kg) & $4.09 \pm 0.25$ & $9.11 \pm 0.44^{* * *}(45.95 \%)$ & $10.89 \pm 0.62^{* * *}(62.26 \%)$ & $11.27 \pm 0.61^{* * *}(65.79 \%)$ & $13.88 \pm 0.75^{* * *}(89.69 \%)$ \\
\hline
\end{tabular}

The results were expressed in Mean \pm SEM (standard mean error) ${ }^{*} p<0.05$, ${ }^{* *} p<0.01$, and ${ }^{* * *} p<0.001$ were considered as statistically significant. The statistical analysis followed by one-way analysis of variance (Dunnett's test) compared to the control. $M D M L=C$ rude methanol extract of $M$. dispermus leaves, $M D H L=n$-hexane fraction of crude methanol extract of $M$. dispermus leaves, $M D T L=$ Carbon tetrachloride fraction of crude methanol extract of $M$. dispermus leaves, $M D C L=C h l o r o f o r m$ fraction of crude methanol extract of $M$. dispermus leaves, MDEL = Ethyl acetate fraction of crude methanol extract of $M$. dispermus leaves, MDAL $=A q u e o u s$ fraction of crude methanol extract of $M$. dispermus leaves, MDMS =Crude methanol extract of $M$. dispermus stem barks 
Table 6 Analgesic activity of the investigated extracts of $M$. dispermus leaves and stem barks on tail immersion test

\begin{tabular}{|c|c|c|c|c|c|}
\hline \multirow[t]{2}{*}{ Group } & \multirow[t]{2}{*}{ Dose (mg/kg) } & \multicolumn{4}{|c|}{ Percent (\%) elongation of latency } \\
\hline & & $30 \mathrm{~min}$ & $60 \mathrm{~min}$ & $90 \mathrm{~min}$ & $120 \mathrm{~min}$ \\
\hline $\begin{array}{l}\text { Morphine } \\
\text { sulfate }\end{array}$ & 10 & 57.61 & 65.46 & 67.37 & 71.13 \\
\hline MDML 200 & 200 & 17.03 & 51.71 & 53.91 & 68.30 \\
\hline MDML 400 & 400 & 41.03 & 58.07 & 64.43 & 69.91 \\
\hline MDHL 200 & 200 & 41.95 & 50.68 & 44.67 & 41.67 \\
\hline MDHL 400 & 400 & 56.70 & 60.62 & 61.29 & 51.16 \\
\hline MDTL 200 & 200 & 15.77 & 43.03 & 52.71 & 39.36 \\
\hline MDTL 400 & 400 & 41.29 & 56.23 & 61.75 & 53.07 \\
\hline MDCL 200 & 200 & 10.70 & 37.68 & 43.15 & 46.34 \\
\hline MDCL 200 & 400 & 23.45 & 50.03 & 53.93 & 55.48 \\
\hline MDEL 400 & 200 & 10.60 & 40.59 & 36.43 & 48.19 \\
\hline MDEL 200 & 400 & 41.84 & 56.76 & 52.93 & 60.28 \\
\hline MDAL 400 & 200 & 17.98 & 55.06 & 57.31 & 67.15 \\
\hline MDAL 200 & 400 & 30.13 & 60.81 & 65.76 & 69.94 \\
\hline MDMS 200 & 200 & 27.14 & 50.70 & 34.20 & 64.88 \\
\hline MDMS 400 & 400 & 48.53 & 60.28 & 58.76 & 70.14 \\
\hline
\end{tabular}

The results were expressed in Mean \pm SEM (standard mean error) * $p<0.05$, ${ }^{* *} p<0.01$, and ${ }^{* * *} p<0.001$ were considered as statistically significant. The statistical analysis followed by one-way analysis of variance (Dunnett's test) compared to the control. $\mathrm{MDML}=$ Crude methanol extract of $M$. dispermus leaves, $\mathrm{MDHL}=\mathrm{n}$-hexane fraction of crude methanol extract of $M$. dispermus leaves, $M D T L=$ Carbon tetrachloride fraction of crude methanol extract of $M$. dispermus leaves, $\mathrm{MDCL}=$ Chloroform fraction of crude methanol extract of $M$. dispermus leaves, $\mathrm{MDEL}=$ Ethyl acetate fraction of crude methanol extract of $M$. dispermus leaves, $M D A L=$ Aqueous fraction of crude methanol extract of $M$. dispermus leaves, $\mathrm{MDMS}=$ Crude methanol extract of $M$. dispermus stem barks

rectal temperature produced by these extracts conferred in Table 9.

\section{Discussion}

The preliminary phytochemical analysis showed that crude methanol extract of leaves, its solvent fractions, and crude methanol extracts of stem barks of $M$. dispermus contain a mixture of phytochemical compounds that had potential biological and therapeutic activities $[43,44]$. Therefore this species was expected to have many medicinal uses. The present research on this plant showed that the crude MDML and MDMS along with some fractions possess considerable thrombolytic, cytotoxic, analgesic, and antipyretic properties.

Several types of research have been conducted to find antithrombotic agents from different types of medicinal plants. From the current study, it was evident that the clot dissolution did not occur after the addition of distilled water to the clot. In contrast, standard streptokinase lysed almost all the clots. During the investigation, it was observed that MDHL and MDMS were observed to have a significant thrombolytic effect. Among those, MDHL showed a significant thrombolytic effect with no potential cytotoxic effect. The clot lysis effect of these investigated extracts increased with the increase in their concentration. Since the thrombolytic effect of those extracts was comparable to that of Streptokinase, they possibly acted through the formation of a complex with plasminogen which could convert additional plasminogen to plasmin. Plasmin lysed clots by breaking down the fibrinogen and fibrin contained in a clot [45]. Although the role of alkaloids, saponins, tannins, terpenoids, and flavonoids as thrombolytic agents is still unknown, their presence in those extracts might contribute to thrombolysis through platelet aggregation [46, 47].

In the cytotoxicity evaluation study of plant extracts by brine shrimp lethality assay, $\mathrm{LC}_{50}$ values lower than $1000 \mu \mathrm{g} / \mathrm{ml}$ were considered cytotoxic [42]. From the current observation, it was found that vincristine sulfate, a known anticancer agent had the lowest $\mathrm{LC}_{50}$ value of $0.14 \mu \mathrm{g} / \mathrm{ml}$ which proved its highly potent cytotoxic activity. In this study, MDML extract and its MDHL and MDTL fractions were evident as a highly non-cytotoxic agent. But MDCL, MDEL, MDAL fractions of crude MDML, and MDMS were evident to possess cytotoxic activity. Hence they could be further investigated for their potential as anticancer agents. Preliminary phytochemical screening revealed the presence of flavonoids, glycosides, saponin, alkaloids, and steroids in the investigated extracts which might contribute to their cytotoxic activities $[48,49]$. Flavonoids exert their cytotoxic activity by increasing the production of cellular ROS levels [50]. Saponins initiate apoptosis of cancer cells [51]. Previous studies suggested that alkaloids can inhibit the proliferation of many cancer cells [52].

The acetic acid-induced writhing method was used to evaluate the peripheral analgesic activity of the investigated extracts which used the reaction of animals to painful chemical stimuli $[53,54]$. In this method, dilute acetic acid produced a writhing reflex in animals by activating the chemosensitive nociceptors [55]. It produced a localized inflammatory response due to the release of free Arachidonic acid from tissue phospholipid via COX and produced prostaglandins in the peritoneal fluid. It causes swelling and the release of endogenous substances that stimulate pain nerve endings [56]. The crude MDML, and its MDTL, MDCL, and MDEL fractions at the dose of 200 and $400 \mathrm{mg} / \mathrm{kg}$ showed a significant and higher percentage (\%) of inhibition of abdominal writhing in mice as compared to control whereas the standard Diclofenac sodium, an NSAID at $50 \mathrm{mg} / \mathrm{kg}$ showed the highest activity. The significant $(P<0.001)$ dose-dependent analgesic effect of the investigated extracts was hypothesized to be mediated through peripheral pain mechanism and suppression of prostaglandin pathway as they had a comparable analgesic effect like NSAID [57]. 
Table 7 Analgesic effect of the investigated extracts of $M$. dispermus leaves and stem barks on formalin-induced paw licking test

\begin{tabular}{|c|c|c|c|c|}
\hline \multirow[t]{2}{*}{ Group } & \multicolumn{2}{|l|}{ 0-5 min (early phase) } & \multicolumn{2}{|c|}{$15-30 \mathrm{~min}$ (late phase) } \\
\hline & Paw licking time (s) & $\begin{array}{l}\text { Percent inhibition of } \\
\text { pain }\end{array}$ & Paw licking time (s) & $\begin{array}{l}\text { Percent } \\
\text { Inhibition of } \\
\text { PAIN }\end{array}$ \\
\hline Control & $52.98 \pm 4.73$ & - & $72.76 \pm 5.55$ & - \\
\hline Morphine sulfate (10 mg/kg) & $8.71 \pm 0.66^{* * *}$ & 83.55 & $4.90 \pm 0.66^{* * *}$ & 93.27 \\
\hline MDML (200 mg/kg) & $23.72 \pm 3.43^{* *}$ & 55.23 & $18.49 \pm 1.23^{* * *}$ & 74.59 \\
\hline MDML (400 mg/kg) & $21.51 \pm 3.83^{* *}$ & 59.40 & $12.57 \pm 1.95^{* * *}$ & 82.72 \\
\hline MDHL (200 mg/kg) & $49.61 \pm 8.07$ & 6.37 & $43.65 \pm 2.25^{* * *}$ & 40.02 \\
\hline MDHL (400 mg/kg) & $37.96 \pm 6.82$ & 28.35 & $18.27 \pm 3.42^{* * *}$ & 74.89 \\
\hline MDTL (200 mg/kg) & $41.76 \pm 3.63$ & 21.18 & $28.17 \pm 4.74^{* * *}$ & 61.29 \\
\hline MDTL (400 mg/kg) & $34.54 \pm 6.81$ & 34.81 & $12.20 \pm 2.13^{* * *}$ & 83.23 \\
\hline MDCL (200 mg/kg) & $49.76 \pm 5.05$ & 6.08 & $29.70 \pm 3.61^{* * *}$ & 59.18 \\
\hline MDCL (400 mg/kg) & $32.68 \pm 4.05$ & 38.31 & $25.43 \pm 4.37^{* * *}$ & 65.05 \\
\hline MDEL (200 mg/kg) & $52.36 \pm 6.69$ & 1.17 & $14.98 \pm 2.68^{* * *}$ & 79.41 \\
\hline MDEL (400 mg/kg) & $33.17 \pm 4.87$ & 37.39 & $8.87 \pm 1.06^{* * *}$ & 87.80 \\
\hline MDAL (200 mg/kg) & $46.85 \pm 5.20$ & 11.58 & $63.95 \pm 4.91$ & 12.12 \\
\hline MDAL (400 mg/kg) & $29.71 \pm 4.42^{*}$ & 43.93 & $19.72 \pm 3.08^{* * *}$ & 72.90 \\
\hline MDMS (200 mg/kg) & $45.97 \pm 4.52$ & 13.23 & $16.65 \pm 2.26^{* * *}$ & 77.12 \\
\hline MDMS (400 mg/kg) & $24.21 \pm 2.34^{* *}$ & 54.30 & $7.56 \pm 0.62^{* * *}$ & 89.61 \\
\hline
\end{tabular}

The results were expressed in Mean \pm SEM (standard mean error) ${ }^{*} p<0.05,{ }^{* *} p<0.01$, and ${ }^{* * *} p<0.001$ were considered as statistically significant. The statistical analysis followed by one-way analysis of variance (Dunnett's test) compared to the control. MDML $=$ Crude methanol extract of $M$. dispermus leaves, MDHL $=\mathrm{n}$-hexane fraction of crude methanol extract of $M$. dispermus leaves, MDTL $=$ Carbon tetrachloride fraction of crude methanol extract of $M$. dispermus leaves, $\mathrm{MDCL}=\mathrm{Chloroform}$ fraction of crude methanol extract of $M$. dispermus leaves, MDEL = Ethyl acetate fraction of crude methanol extract of $M$. dispermus leaves, $M D A L=A q u e o u s$ fraction of crude methanol extract of $M$. dispermus leaves, MDMS $=$ Crude methanol extract of $M$. dispermus stem barks

Table 8 Antipyretic effect of the investigated extracts of $M$. dispermus leaves and stem barks on brewer's yeast-induced pyrexia test

\begin{tabular}{|c|c|c|c|c|c|c|}
\hline \multirow[t]{2}{*}{ Group } & \multirow{2}{*}{$\begin{array}{l}\text { Normal rectal } \\
\text { temperature }\left({ }^{\circ} \mathrm{F}\right)\end{array}$} & \multirow{2}{*}{$\begin{array}{l}\text { After yeast } \\
\text { administration }\end{array}$} & \multicolumn{4}{|c|}{ Rectal temperature after drug administration $\left({ }^{\circ} \mathrm{F}\right)$} \\
\hline & & & $1 \mathrm{~h}$ & $2 \mathrm{~h}$ & $3 \mathrm{~h}$ & $4 \mathrm{~h}$ \\
\hline Control & $97.34 \pm 0.7$ & $100.96 \pm 0.32$ & $101.72 \pm 0.37$ & $102.40 \pm 0.30$ & $102.42 \pm 0.34$ & $102.12 \pm 0.35$ \\
\hline Paracetamol (150 mg/kg) & $96.82 \pm 0.62$ & $100.48 \pm 0.27$ & $98.08 \pm 0.32^{* * *}$ & $97.48 \pm 0.34^{* * *}$ & $97.12 \pm 0.47^{* * *}$ & $96.82 \pm 0.53^{* * *}$ \\
\hline MDML (200 mg/kg) & $97.02 \pm 0.66$ & $99.82 \pm 0.10$ & $98.96 \pm 0.28^{* * *}$ & $98.10 \pm 0.38^{* * *}$ & $97.62 \pm 0.41^{* * *}$ & $97.84 \pm 0.40^{* * *}$ \\
\hline MDML (400 mg/kg) & $98.50 \pm 0.42$ & $100.06 \pm 0.42$ & $99.54 \pm 0.19^{* * *}$ & $98.96 \pm 0.28^{* * *}$ & $98.68 \pm 0.31^{* * *}$ & $98.88 \pm 0.26^{* * *}$ \\
\hline MDHL (200 mg/kg) & $97.22 \pm 0.71$ & $100.76 \pm 0.42$ & $100.30 \pm 0.49^{* * *}$ & $99.90 \pm 0.47^{* * *}$ & $98.90 \pm 0.38^{* * *}$ & $98.30 \pm 0.33^{* * *}$ \\
\hline MDHL (400 mg/kg) & $98.06 \pm 0.30$ & $100.34 \pm 0.42$ & $99.66 \pm 0.48^{* * *}$ & $98.76 \pm 0.41^{* * *}$ & $98.30 \pm 0.30^{* * *}$ & $98.16 \pm 0.33^{* * *}$ \\
\hline MDTL (200 mg/kg) & $98.60 \pm 0.20$ & $101.06 \pm 0.19$ & $101.48 \pm 0.15$ & $100.64 \pm 0.14^{* *}$ & $99.14 \pm 0.34^{* * *}$ & $99.30 \pm 0.32^{* * *}$ \\
\hline MDTL (400 mg/kg) & $97.58 \pm 0.47$ & $99.98 \pm 0.13$ & $100.88 \pm 0.35$ & $99.24 \pm 0.35^{* * *}$ & $98.08 \pm 0.29^{* * *}$ & $97.62 \pm 0.34^{* * *}$ \\
\hline MDCL (200 mg/kg) & $97.88 \pm 0.48$ & $101.28 \pm 0.21$ & $101.42 \pm 0.24$ & $101.62 \pm 0.26$ & $99.58 \pm 0.27^{* * *}$ & $98.74 \pm 0.19^{* * *}$ \\
\hline MDCL (400 mg/kg) & $97.10 \pm 0.37$ & $100.86 \pm 0.27$ & $101.08 \pm 0.30$ & $101.48 \pm 0.40$ & $98.80 \pm 0.28^{* * *}$ & $97.82 \pm 0.10^{* * *}$ \\
\hline MDEL (200 mg/kg) & $97.02 \pm 0.55$ & $100.92 \pm 0.37$ & $99.80 \pm 0.28^{* *}$ & $99.18 \pm 0.26^{* * *}$ & $98.44 \pm 0.18^{* * *}$ & $98.16 \pm 0.15^{* * *}$ \\
\hline MDEL (400 mg/kg) & $97.32 \pm 0.30$ & $100.46 \pm 0.18$ & $99.32 \pm 0.13^{* * *}$ & $98.50 \pm 0.29^{* * *}$ & $97.64 \pm 0.37^{* * * *}$ & $97.42 \pm 0.28^{* * *}$ \\
\hline MDAL (200 mg/kg) & $96.68 \pm 0.33$ & $100.52 \pm 0.29$ & $100.66 \pm 0.32$ & $101.16 \pm 0.3$ & $98.88 \pm 0.38^{* * *}$ & $98.74 \pm 0.37^{* * *}$ \\
\hline MDAL (400 mg/kg) & $97.38 \pm 0.31$ & $101.28 \pm 0.42$ & $101.54 \pm 0.43$ & $100.42 \pm 0.37^{* *}$ & $98.80 \pm 0.34^{* * *}$ & $98.34 \pm 0.20^{* * *}$ \\
\hline MDMS (200 mg/kg) & $97.66 \pm 0.65$ & $100.08 \pm 0.15$ & $101.00 \pm 0.28$ & $99.92 \pm 0.23^{* * *}$ & $98.62 \pm 0.44^{* * *}$ & $98.72 \pm 0.40^{* * *}$ \\
\hline MDMS (400 mg/kg) & $96.64 \pm 0.40$ & $99.48 \pm 0.44$ & $100.32 \pm 0.25^{*}$ & $98.90 \pm 0.54^{* * *}$ & $97.30 \pm 0.29^{* * *}$ & $97.10 \pm 0.32^{* * *}$ \\
\hline
\end{tabular}

The results were expressed in Mean \pm SEM (standard mean error) ${ }^{*} p<0.05,{ }^{* *} p<0.01$, and ${ }^{* * *} p<0.001$ were considered as statistically significant. The statistical analysis followed by one-way analysis of variance (Dunnett's test) compared to the control. MDML $=$ Crude methanol extract of $M$. dispermus leaves, $\mathrm{MDHL}=\mathrm{n}$-hexane fraction of crude methanol extract of $M$. dispermus leaves, MDTL = Carbon tetrachloride fraction of crude methanol extract of $M$. dispermus leaves, $\mathrm{MDCL}=\mathrm{Ch}$ loroform fraction of crude methanol extract of $M$. dispermus leaves, MDEL = Ethyl acetate fraction of crude methanol extract of $M$. dispermus leaves, $\mathrm{MDAL}=\mathrm{Aqueous}$ fraction of crude methanol extract of $M$. dispermus leaves, MDMS $=$ Crude methanol extract of $M$. dispermus stem barks 
Table 9 Percent decrease in rectal temperature of all test samples of $M$. dispermus leaves and stem barks on brewer's yeastinduced pyrexia test

\begin{tabular}{lcccc}
\hline Group & \multicolumn{4}{l}{$\begin{array}{l}\text { Percent decrease in rectal temperature } \\
\text { (\%) after drug treatment }\end{array}$} \\
\cline { 2 - 5 } & $\mathbf{1} \mathbf{h}$ & $\mathbf{2} \mathbf{h}$ & $\mathbf{3} \mathbf{~ h}$ & $\mathbf{4} \mathbf{~}$ \\
\hline Paracetamol (150 mg/kg) & 65.57 & 81.97 & 91.8 & 100 \\
MDML (200 mg/kg) & 30.71 & 61.43 & 78.57 & 70.71 \\
MDML (400 mg/kg) & 33.33 & 70.51 & 88.46 & 75.64 \\
MDHL (200 mg/kg) & 12.99 & 24.29 & 52.54 & 69.49 \\
MDHL (400 mg/kg) & 29.82 & 69.3 & 89.47 & 95.61 \\
MDTL (200 mg/kg) & - & 17.07 & 78.05 & 71.54 \\
MDTL (400 mg/kg) & - & 30.83 & 79.17 & 98.33 \\
MDCL (200 mg/kg) & - & - & 50.00 & 74.71 \\
MDCL (400 mg/kg) & - & - & 54.79 & 80.85 \\
MDEL (200 mg/kg) & 28.72 & 44.62 & 63.59 & 70.77 \\
MDEL (400 mg/kg) & 36.31 & 62.42 & 89.81 & 96.82 \\
MDAL (200 mg/kg) & - & - & 42.71 & 46.35 \\
MDAL (400 mg/kg) & - & 22.05 & 63.59 & 75.38 \\
MDMS (200 mg/kg) & - & 6.61 & 60.33 & 56.2 \\
MDMS (400 mg/kg) & - & 20.42 & 76.76 & 83.8 \\
\hline
\end{tabular}

The results were expressed in Mean \pm SEM (standard mean error) * $p<0.05$, ${ }^{* *} p<0.01$, and ${ }^{* * *} p<0.001$ were considered as statistically significant. The statistical analysis followed by one-way analysis of variance (Dunnett's test) compared to the control. MDML $=$ Crude methanol extract of $M$. dispermus leaves, $\mathrm{MDHL}=n$-hexane fraction of crude methanol extract of $M$. dispermus leaves, $\mathrm{MDTL}=$ Carbon tetrachloride fraction of crude methanol extract of $M$. dispermus leaves, $\mathrm{MDCL}=$ Chloroform fraction of crude methanol extract of $M$. dispermus leaves, $\mathrm{MDEL}=$ Ethyl acetate fraction of crude methanol extract of $M$. dispermus leaves, $M D A L=$ Aqueous fraction of crude methanol extract of $M$. dispermus leaves, $\mathrm{MDMS}=$ Crude methanol extract of $M$. dispermus stem barks,

' - 'indicates the reduction of temperature didn't occur at a time interval

The central analgesic activity evaluation model of tail immersion used thermal stimuli in this regard [54, 58]. In this model, sensory nerves sensitized the nociceptors, increased the pain thresholds [59], and the involvement of prostaglandins was decreased [60]. In the current study, the increase in \%MPE, PRT, or latency period indicated the level of analgesia of drug or extract. MDML, MDEL, MDAL, and MDMS at 200 and $400 \mathrm{mg} /$ $\mathrm{kg}$ showed a significant increase in PRT, higher percentage (\%) of MPE, and elongation until $120 \mathrm{~min}$ as compared to control in a dose-dependent manner whereas the reference standard morphine sulfate $(10 \mathrm{mg} / \mathrm{kg})$ also increased those indices significantly. Since their effect was comparable to narcotic drug morphine sulfate, those extracts possibly showed an opiates-like mechanism of action indicating the spinal and supraspinal pathways of analgesia [59].

The analgesic model of formalin-induced paw licking test usually involved two distinct phases: an early transient phase, which occurred in the first 5 min that reflected direct stimulation of nociceptors, and a late tonic phase, evident 15 to $30 \mathrm{~min}$ after injection that might be associated with the release of inflammatory mediators [61, 62]. In this method, MDML and MDMS showed significant inhibition of induced pain during both early and late phases of the study as compared to control. MDTL and MDEL fractions also showed highly significant effectiveness in pain inhibition during the late phase that demonstrated its dominance as a peripheral analgesic. Several reports had shown the analgesic properties of flavonoids, tannins, and other polyphenolic compounds in different experimental animal models [63]. The presence of those phytochemicals in the extracts could be attributed to their effectiveness as analgesic agents.

In the brewer's yeast-induced pyrexia model, the proteins present in yeast were responsible for fever induction through an inflammatory reaction [64]. In this experiment, $\mathrm{n}$-hexane, carbon tetrachloride and ethyl acetate fractions of crude methanol extracts of $M$. dispermus leaves at the dose of 200 and $400 \mathrm{mg} / \mathrm{kg}$ exhibited an increasing percentage (\%) of reduction of hyperthermia in a significant $(P<0.001)$ dose-dependent manner which persists up to $4 \mathrm{~h}$. This effect was comparable to the standard drug paracetamol. Hence, there might be a possible mechanism of antipyretic action by inhibiting the synthesis of prostaglandins like paracetamol [65]. MDTL and MDEL exhibited both peripheral analgesic effect and antipyretic effect possibly showed action through inhibition of the synthesis of prostaglandins. So, they might act as cyclooxygenase inhibitors [66]. Furthermore, several multi-processes or mediators such as bacterial endotoxin (lipopolysaccharide), endogenous pyrogen, and interleukin- $1 \alpha$ were emphasizing the pathogenesis of fever. Inhibition of any of these mediators might bring about antipyresis [67]. The antipyretic activity could be triggered by the presence of flavonoids, saponins, glycosides, tannins in the investigated extracts [68].

\section{Conclusions}

The current research found that the different extracts of $M$. dispermus leaves and stem barks revealed the presence of a mixture of phytochemicals and exhibited potent thrombolytic, anticancer, analgesic, and antipyretic effects. It may have concluded an important contribution in the herbal medicine researches and further advanced researches must be conducted on this medicinal plant to discover its more precise physiologic effect.

\section{Abbreviations}

DW: Distilled water; SK: Streptokinase; GABA: Gamma amino butyric acid; MPE: Maximal possible effect; PG: Prostaglandins; LC: Lethal concentration; PRT: Pain reaction time; NSAID: Non-steroidal anti-inflammatory drugs. 


\begin{abstract}
Acknowledgements
The authors acknowledge the student research fellowship provided by the Ministry of Science and Technology (NST), Govt. of the Peoples' Republic of Bangladesh. Authors' also grateful to Professor Dr. Shaikh Bokhtear Uddin, Department of Botany, University of Chittagong, and a renowned Taxonomist of Bangladesh for his help in the identification of our prospective medicinal plant.
\end{abstract}

\section{Authors' contributions}

MKH designed the experiments, conception, and supervised the research work. SRA collected the plant material, performed the pharmacological assays, statistical analysis, and drafted the manuscript. NMP, SSD, and SWJ contributed to performing pharmacological analysis. MRI helps in the statistical analysis and write-up of the manuscript. MRI and BHK critically revised the manuscript, provided punctual assistance, and gave the final approval for the submission of a revised version. Finally, all authors gave their final consent for the submission. All authors read and approved the final manuscript.

\section{Funding}

This study was funded by the Ministry of Science and Technology, Govt. of Peoples' Republic of Bangladesh (Grant No. BS-312). The funders have no role in the design of the study, laboratory work, data collection, analysis, evaluation, interpretation of data, and the write-up of the manuscript.

\section{Availability of data and materials}

The datasets used and/or analyzed during the current study are available from the corresponding author on reasonable request.

\section{Declarations}

\section{Ethics approval and consent to participate}

All authors hereby declare that "Principles of laboratory animal care" (NIH publication No. 85-23, revised 1985) were followed, as well as specific national laws where applicable. All experiments have been examined and approved by the ethical committee of the University of Chittagong, Bangladesh under the approval no-cc98056.

\section{Consent for publication}

Not applicable.

\section{Competing interests}

The authors declare that they have no competing interests.

Received: 1 February 2021 Accepted: 10 August 2021

Published online: 23 August 2021

\section{References}

1. Sofowora A (1982) Medicinal plants and traditional medicine in Africa. Wiley

2. Mannan A, Kawser M, Ahmed A, Islam NN, Alam S, Emon MAEK, Gupta SD (2011) Assessment of antibacterial, thrombolytic and cytotoxic potential of Cassia alata seed oil. J Appl Pharm Sci 1(9):56

3. Collen D (1990) Coronary thrombolysis: streptokinase or recombinant tissue-type plasminogen activator? Ann Intern Med 112(7):529-538

4. Nicolini FA, Nichols WW, Mehta JL, Saldeen TG, Schofield R, Ross M, Player DW, Pohl GB, Mattsson C (1992) Sustained reflow in dogs with coronary thrombosis with $\mathrm{K} 2 \mathrm{P}$, a novel mutant of tissue-plasminogen activator. J Am Coll Cardiol 20(1):228-235

5. Rouf SA, Moo-Young M, Chisti Y (1996) Tissue-type plasminogen activator: characteristics, applications and production technology. Biotechnol Adv 14(3):239-266

6. Awadh N, Ronco JJ, Bernstein V, Gilks B, Wilcox P (1994) Spontaneous pulmonary hemorrhage after thrombolytic therapy for acute myocardial infarction. Chest 106(5):1622-1624

7. Cooper JP, Quarry DP, Beale DJ, Chappell AG (1994) Life-threatening, localized angio-oedema associated with streptokinase. Postgrad Med J 70(826):592
8. Rahman MA, Sultana R, Emran TB, Islam MS, Rahman MA, Chakma JS, Rashid H-u, Hasan CMM (2013) Effects of organic extracts of six Bangladeshi plants on in vitro thrombolysis and cytotoxicity. BMC Complement Altern Med 13(1):25

9. Uddin MS, Millat MS, Islam MS, Hussain MS, Uddin MG, Siddiqui SA, Ferdous M (2020) Exploration of in vitro thrombolytic, anthelminthic, cytotoxic and in vivo anxiolytic potentials with phytochemical screening of flowers of Brassica nigra. Futur J Pharm Sci 6(1):1-9

10. Schug SA, Daly HC, Stannard KJ (2011) Pathophysiology of pain. In: Fitridge R, Thompson M (eds) Mechanisms of vascular disease: A reference book for vascular specialists. University of Adelaide Press

11. Sen S, Chakraborty R, De B, Ganesh T, Raghavendra H, Debnath S (2010) Analgesic and anti-inflammatory herbs: a potential source of modern medicine. Int J Pharm Sci Res 1(11):32

12. Hewitt D, Hargreaves R, Curtis S, Michelson D (2009) Challenges in analgesic drug development. Clin Pharmacol Ther 86:447-450

13. Walter EJ, Hanna-Jumma S, Carraretto M, Forni L (2016) The pathophysiological basis and consequences of fever. Crit Care 20(1):1-10

14. Mate G, Naikwade N, Magdum C, Chowki A, Patil S (2008) Evaluation of anti-nociceptive activity of Cissus quadrangularis on albino mice. Int I J Green Pharma 2:118-121

15. Pan S-Y, Litscher G, Gao S-H, Zhou S-F, Yu Z-L, Chen H-Q, Zhang S-F, Tang M-K, Sun J-N, Ko K-M (2014) Historical perspective of traditional indigenous medical practices: the current renaissance and conservation of herbal resources. Evid-Based Complement Alternat Med. 2014:525340

16. Chopra RN, Nayar SL, Chopra IC (1956) Glossary of Indian medicinal plants, vol 1. Council of Scientific \& Industrial Research

17. Phillipson JD (2001) Phytochemistry and medicinal plants. Phytochem 56(3):237-243

18. Cragg GM, Newman DJ (2005) Plants as a source of anti-cancer agents. J Ethnopharmacol 100(1-2):72-79

19. Rates SMK (2001) Plants as source of drugs. Toxicon 39(5):603-613

20. Queiroz EF, Wolfender J-L, Hostettmann K (2009) Modern approaches in the search for new lead antiparasitic compounds from higher plants. Curr Drug Targets 10(3):202-211

21. Panyaphu K, Van On T, Sirisa-Ard P, Srisa-Nga P, ChansaKaow S, Nathakarnkitkul S (2011) Medicinal plants of the Mien (Yao) in Northern Thailand and their potential value in the primary healthcare of postpartum women. J Ethnopharmacol 135(2):226-237

22. Ong HG, Ling SM, Win TTM, Kang D-H, Lee J-H, Kim Y-D (2018) Ethnobotany of wild medicinal plants used by the Müün ethnic people: a quantitative survey in southern Chin state. Myanmar J Herb Med 13:91-96

23. Chanwitheesuk A, Teerawutgulrag A, Rakariyatham N (2005) Screening of antioxidant activity and antioxidant compounds of some edible plants of Thailand. Food Chem 92:491-497

24. Kupchan SM, Tsou G, Sigel CW (1973) Datiscacin, a novel cytotoxic cucurbitacin 20-acetate from Datisca glomerata. J Org Chem 38(7):1420-1421

25. VanWagenen BC, Larsen R, Cardellina JH, Randazzo D, Lidert ZC, Swithenbank C (1993) Ulosantoin, a potent insecticide from the sponge Ulosa ruetzleri. J Org Chem 58(2):335-337

26. Sofowora A (1996) Research on medicinal plants and traditional medicine in Africa. J Altern Complement Med 2(3):365-372

27. Trease G, Evans W (1989) Pharmacognosy. Bailliere Tindall Ltd

28. Harborne J (1973) Phytochemicals methods. Chapman and Hall Ltd

29. Al-Araby S, Rahman MA, Chowdhury MA, Das R, Chowdhury T, Hasan CMM, Afroze M, Hashem M, Hajjar D, Alelwani W (2020) Padina tenuis (marine alga) attenuates oxidative stress and streptozotocin-induced type 2 diabetic indices in Wistar albino rats. S Afr J Bot 128:87-100

30. Prasad S, Kashyap RS, Deopujari JY, Purohit HJ, Taori GM, Daginawala HF (2006) Development of an in vitro model to study clot lysis activity of thrombolytic drugs. Thrombosis J 4(1):14

31. Mosaddik MA, Haque ME (2003) Cytotoxicity and antimicrobial activity of goniothalamin isolated from Bryonopsis laciniosa. Phytother Res 17(10):1155-1157

32. Sathasivam P, Lakshmi T (2017) Brine shrimp lethality assay of Sesbania grandiflora ethanolic extract - in vitro study. J Adv Pharm Edu Res $7(1): 28-30$

33. Koster R, Anderson M, de Beer EJ (1959) Acetic acid for analgesic screening. In: Fed Proc, p 412 
34. Dambisya YM, Lee T-L, Sathivulu V, Jais AMM (1999) Influence of temperature, $\mathrm{pH}$ and naloxone on the antinociceptive activity of Channa striatus (haruan) extracts in mice. J Ethnopharmacol 66(2):181-186

35. Di Stasi LC, Costa M, Mendaçolli SL, Kirizawa M, Gomes C, Trolin G (1988) Screening in mice of some medicinal plants used for analgesic purposes in the state of Sao Paulo. J Ethnopharmacol 24:205-211

36. Malairajan P, Gopalakrishnan G, Narasimhan S, Veni KJK (2006) Analgesic activity of some Indian medicinal plants. J Ethnopharmacol 106(3):425-428

37. Fan S-H, Ali NA, Basri DF (2014) Evaluation of analgesic activity of the methanol extract from the galls of Quercus infectoria (Olivier) in rats. EvidBased Complement Alternat Med. https://doi.org/10.1155/2014/976764

38. Kumawat RK, Kumar S, Sharma S (2012) Evaluation of analgesic activity of various extracts of Sida tiagii Bhandari. Acta Pol Pharm 69:1103-1109

39. Hunskaar S, Hole K (1987) The formalin test in mice: dissociation between inflammatory and non-inflammatory pain. Pain 30:103-114

40. Adams S, Hebborn P, Nicholson J (1968) Some aspects of the pharmacology of ibufenac, a non-steroidal anti-inflammatory agent. J Pharm Pharmacol 20:305-312

41. Muhammad N, Saeed M, Khan H (2012) Antipyretic, analgesic and antiinflammatory activity of Viola betonicifolia whole plant. BMC Complement Altern Med 12:59

42. Meyer B, Ferrigni N, Putnam J, Jacobsen L, Dj N, McLaughlin JL (1982) Brine shrimp: a convenient general bioassay for active plant constituents. Planta Med 45(05):31-34

43. Benedec D, Vlase L, Oniga I, Mot A, Damian G, Hanganu D, Duma M, Silaghi-Dumitrescu R (2013) Polyphenolic composition, antioxidant and antibacterial activities for two Romanian subspecies of Achillea distans Waldst. et Kit. ex Willd. Molecules 18(8):8725-8739

44. Rao BG, Rao ES, Rao TM (2012) Quantification of phytochemical constituents and in-vitro antioxidant activity of Mesua ferrea leaves. Asian Pac J Trop Biomed 2(2):S539-S542

45. Banerjee A, Chisti Y, Banerjee U (2004) Streptokinase-a clinically useful thrombolytic agent. Biotechnol Adv 22(4):287-307

46. Islam A, Hussain MS, Sen N, Abedin F, Millat MS, Islam MS, Das A, Kar A, Hossain M (2017) Investigation of in vitro thrombolytic and antihelminthic activity and in vivo anxiolytic and antidepressant potentiality with phytochemical nature of methanolic extract of Leucas lavandulifolia. Sustain Chem Pharm 6:61-66

47. Klafke JZ, Arnoldi da Silva M, Fortes Rossato M, Trevisan G, Banderó Walker Cl, Martins Leal CA, Olschowsky Borges D, Chitolina Schetinger MR, Noal Moresco R, Medeiros Frescura Duarte MM et al (2012) Antiplatelet, antithrombotic, and fibrinolytic activities of Campomanesia xanthocarpa. Evid-Based Complement Alternat Med 2012:954748

48. Dhar M, Dhar M, Dhawan B, Mehrotra B, Srimal R, Tandon J (1973) Screening of Indian plants for biological activity. IV. Indian J Exp Biol 11(1):43-54

49. Badami S, Manohara Reddy S, Kumar E, Vijayan P, Suresh B (2003) Antitumor activity of total alkaloid fraction of Solanum pseudocapsicum leaves. Phytother Res 17(9):1001-1004

50. Matsuo M, Sasaki N, Saga K, Kaneko T (2005) Cytotoxicity of flavonoids toward cultured normal human cells. Biol Pharm Bull 28(2):253-259

51. Alam F, us Saqib QN, Waheed A (2017) Cytotoxic activity of extracts and crude saponins from Zanthoxylum armatum DC. against human breast (MCF-7, MDA-MB-468) and colorectal (Caco-2) cancer cell lines. BMC Complement Altern Med 17(1):368
52. Lamchouri F, Zemzami M, Jossang A, Abdellatif A, Israili ZH, Lyoussi B (2013) Cytotoxicity of alkaloids isolated from Peganum harmala seeds. Pak J Pharm Sci 26(4):699-706

53. Hasan SR, Hossain M, Akter R, Jamila M, Mazumder M, Alam M, Faruque A, Rana S, Rahman S (2010) Analgesic activity of the different fractions of the aerial parts of Commelina benghalensis Linn. Int J Pharmacol 6(1):63-67

54. George K, Eric W, David D, George A (2009) Antinociceptive effects of Newboulia laveis (P. Beauv) stem bark extract in rat model. Pharmacog Mag 17:49-54

55. Ezeja M, Omeh Y, Ezeigbo I, Ekechukwu A (2011) Evaluation of the analgesic activity of the methanolic stem bark extract of Dialium guineense (Wild). Ann Med Health Sci Res 1:55-62

56. Afsar T, Khan MR, Razak S, Ullah S, Mirza B (2015) Antipyretic, antiinflammatory and analgesic activity of Acacia hydaspica R. Parker and its phytochemical analysis. BMC Complement Altern Med 15(1):1-12

57. Ferdous M, Rouf R, Shilpi JA, Uddin SJ (2008) Antinociceptive activity of the ethanolic extract of Ficus racemosa Lin. (Moraceae). Orient Pharma Exp Med 8:93-96

58. Björkman R (1995) Central antinociceptive effects of non-steroidal antiinflammatory drugs and paracetamol. Experimental studies in the rat. Acta Anaesthesiol Scand Suppl 103:1-44

59. Shah SMM, Shah SMH (2015) Phytochemicals, antioxidant, antinociceptive and anti-inflammatory potential of the aqueous extract of Teucrium stocksianum bioss. BMC Complement Altern Med 15(1):1-7

60. Bachhav R, Gulecha V, Upasani C (2009) Analgesic and anti-inflammatory activity of Argyreia speciosa root. Ind J Pharmacol 41:158

61. Dubuisson D, Dennis SG (1977) The formalin test: a quantitative study of the analgesic effects of morphine, meperidine, and brain stem stimulation in rats and cats. Pain 4:161-174

62. Rosland JH, Tjølsen A, Mæhle B, Hole K (1990) The formalin test in mice: effect of formalin concentration. Pain 42(2):235-242

63. Krasteva I, Platikanov S, Nikolov S, Kaloga M (2007) Flavonoids from Astragalus hamosus. Nat Prod Res 21(5):392-395

64. Pasin JSM, Ferreira APO, Saraiva ALL, Ratzlaff V, Andrighetto R, Tomazetti $J$ et al (2010) Diacerein decreases TNF- $a$ and IL-1 $\beta$ levels in peritoneal fluid and prevents Baker's yeast-induced fever in young rats. Inflam Res 59:189-196

65. Chandrasekharan N, Dai H, Roos KLT, Evanson NK, Tomsik J, Elton TS et al (2002) COX-3, a cyclooxygenase-1 variant inhibited by acetaminophen and other analgesic/antipyretic drugs: cloning, structure, and expression. Proc Natl Acad Sci 99:13926-13931

66. Yemitan OK, Adeyemi OO (2017) Mechanistic assessment of the analgesic, anti-inflammatory and antipyretic actions of Dalbergia saxatilis in animal models. Pharm Biol 55(1):898-905

67. Srivastava S, Singh P, Jha K, Mishra G, Srivastava S, Khosa R (2013) Antiinflammatory, analgesic and antipyretic activities of aerial parts of Costus speciosus Koen. Ind J Pharma Sci 75:83

68. Mutalik S, Paridhavi K, Rao CM, Udupa N (2003) Antipyretic and analgesic effect of leaves of Solanum melongena Linn. in rodents. Indian J Pharmacol 35(5):312-315

\section{Publisher's Note}

Springer Nature remains neutral with regard to jurisdictional claims in published maps and institutional affiliations. 